\title{
DISSERTAÇÕES DE MESTRADO
}

\section{A Atuação de Ofício do Juiz no Julgamento do Mérito ${ }^{3}$}

\author{
Maristela da Silva Alves
}

\section{RESUMO}

A presente dissertação aborda os poderes do juiz no julgamento de mérito, ou seja, examina as possibilidades da iniciativa judicial sem a prévia provocação das partes, quando se trata do mérito da causa.

Faz-se uma abordagem prévia da estrutura processual, demonstrando :como o sistema possibilita esses pronunciamentos; diferenciando quais são as :tarefas das partes e quais as do juiz na busca de um processo justo e com efetividade. Por isso, estuda-se, também, o principio dispositivo em sentido material e formal.

Na primeira parte, é desenvolvida a estrutura processual: Causapetendi, pedido e defesa. Após, o princípio da correlação e as suas exceções, bem como os princípios que têm como tarefa garantir a correta aplicação dos poderes ex officio.

Na segunda parte, examinam-se as possiveis situações de pronunciamento oficioso e suas conseqüências processuais.

${ }^{3}$ A banca foi composta pelo Professor Doutor Adroaldo Furtado Fabricio, Professor Titular de Direito Processual Civil e Livre Docente da Universidade Federal do Rio Grande do Sul, Doutor en Processo Civil pela Universidade Federal do Rio Grande do Sul; pelo Professor Doutor José Roberto dos Santos Bedaque, Professor associado da Universidade de São Paulo, Doutor em Direito pela Universidade de São Paulo e pelo Professor Doutor José Maria Rosa Tesheiner, Professor adjunto da Universidade Federal do Ro Grande do Sul, Doutor em Processo Civil pela Universidade Federal do Rio Grande do Sul A referida defesa fol presidida pelo Professor Doutor Carlos Aberto Alvato de Oliveira, Professor Titular da Universidade Federal do Rio Grande do Sul, Doutor em Direito pela Universidade de São Paulo, orientador do referido trabaho. 


\title{
A Informação como Direito do Consumidor ${ }^{4}$
}

\author{
Fernanda Nunes Barbosa
}

\section{RESUMO}

Este trabalho tem como objetivo apresentar um panorama do direito à informação nas relações de consumo, partindo da análise da importância assumida pela informação como valor social No âmbito da defesa do consumidor, esse direito adquire ainda maior relevância, uma vez que o desequilibrio informativo se torna evidente, com reflexos não só na esfera econômica dos sujeitos, senão também na esfera pessoal. Nesse sentido, o direito à informação será tratado, no presente estudo, na perspectiva de um direito fundamental.

O direito básico do consumidor à informação, positivado, no Código de Defesa do Consumidor brasileiro, no art. $6^{\circ}$, inc. III, unido à previsão constitucional da defesa do consumidor e do direito fundamental à informação constituem a base legal paza o desenvolvimento da jurisprudência nacional na matéria, que será igualmente objero de exame.

Como dever imposto aos fornecedores, a informação pode constituir tanto um dever principal como um dever anexo, que encontra, no principio da boa-fé, a fonte primordial para sua imposição. Ao lado da boa-fé objetiva, serão examinados, ainda, o ideal de transparência no mercado de consumo e os deveres de proteção, quando se destacará o papel instrumental do dever de informar.

Em una apreciação mais detalhada da lei especial, enfatizaremos o estabelecimento dos deveres de informar como prevenção de danos, bem como nas declarações de vontade.

\footnotetext{
4 à Banca Examinadora composta pelo Professor Doutor Luís Renako Fetreint da Siha, Professor da Pontficia Universidade Católica do Rio Grande do Sul e Doutor em Direito Civil peja Universidade de São Paulo, e pela Professora Doutora Rosângela Lumantelli Cavatharzti, Professora da Universictade Estadual do Rio de Janeiro, Doutora em Direito Civil pela Universidade Federal do Rio de Janeiro, e pelo Professor Doutor José Alcebiades de Olituina Júnior, Professor Tinular da Universidade Federal do Rio Grande do Sul, Doutor pela Universidade Federal de Santa Catarina. A referida banca de defesa de dissertação foi presidida pela Professora Doutora Cláudia Lima Marques, Professora Titular da Universidade Federal do Rio Grande do Sul e Doutora em Direito pela Universidade de Heidelberg - Alemanha, orientadora do referito trabalho.
} 


\title{
Breve Análise Estrutural no Negócio Jurídico de Emprego ${ }^{5}$
}

\author{
Alexandre Corrêa Da Cruz
}

\section{RESUMO}

A presente dissertação versa a respeito da análise do negócio jurídico de emprego.

Para atender de forma satisfatória ao intento a que se propõe, investiga-se a evolução histótica do trabalho subordinado no desenvolver da humanidade, bem como a estruturação normativa desse fenômeno nos vários períodos históricos e, em especial, no ordenamento juridico brasileiro.

Opresente estudo ocupa-se também das várias vertentes teóricas que tentaram buscar uma explicação adequada à narureza jurídica da relação de emprego.

Após um breve apanhado histórico e depois de estabelecidas as premissas teóricas que envolvem a discussão da natureza da relação de emprego, a dissertação tem por escopo a sistematização dogmática dos elementos estruturantes do negócio jurídico de emprego, aceitando para tal que a relação de emprego detém jaez contratual.

\footnotetext{
"1 A Banca Examinadora foi composta pelo Professor Doutor Glênio José Wasserstein Hekman, Professor Adjunto da Universidade Federal do Rio Grande do Sul e Doutor em Direito pela Universidade de São Paulo, pelo Professor Doutor Antônio Maria Rodrigues Freitas lserhard, Professor da Universidade do Vale do Rio dos Sinos e Doutor em Direito pela Universidade Federal de Santa Catarina, e pelo Professor Doutor José Felipe Ledur, Professor do Centro Universitário Ritter dos Reis e Doutor em Direito pela Universidade Federal do Paraná. A referida defesa foi presidida pela Professora Doutora Cláudia Lima Marques, Professora Titular de Direito Internacional Privado da Universidade Federal do Rio Grande do Sul, Doutora em Direito pela Universidade de Heidelberg - Alemanha, e orientadora do referido trabalho. 02-07-2004
} 


\title{
Conceitos e Competências Tributárias ${ }^{6}$
}

\author{
Andrei Pitten Velloso
}

\section{RESUMO}

Esta dissertação versa sobre a construção de conceitos a partir dos signos empregados pela Constituição de 1988 para outorgar competências tributárias às pessoas politicas. Analisam-se as principais teorias acerca do tema, assim como as peculiaridades dos enunciados correlatos, do sistema constitucional tributário e, ainda, das normas atributivas de competências. Também se expõem as características conceituais e se formula uma classificação dos conceitos constitucionats em função de sua origem. Refutando-se posiçoes apriorísticas, apresenta-se a proposta de um modelo interpretativo e diretrizes metodológicas específicas para a determinação de tais conceitos, reconhecendo-se a possibilidade de a Constituição incorporar conceitos pré-constitucionais ou consagrar conceitos autônomos, o que há de ser conclú́do a posteriori, após o encerramento do trabalho interpretativo. Formulam-se, não obstante, regras prima facie de incorporação dos conceitos preexisrentes, que attibuem o onus argumentativo àquele que defender a adoção de um conceito autônomo ou de um conceito preexistente extrajuridico.

\footnotetext{
- A Banca Examinadora foi composta pelo Professor Doutor Aicides Jorge Costa, Professor Titular da Universidade de São Paulo (Aposentado) e Livre Docência em Direito pela Universidade de São Paulo, pelo Professor Doutor Cezar Saldanha Souza Junior, Professor da Universidade Federal do Rio Grande do Sul e Doutor em Direito pela Universidade de São Paulo, e pelo Professor Doutor Paulo de Barros Carvalho, Professor Livre Docente da Pontificia Unjversidade Católica de São Paulo e Titular da Universidade de São Panio e Doutor em Direito pela Pontificia Universidacie Católica de São Paulo. A referida defesa foi presidida pelo Professor Doutor Humberto Bergmann Ávila, Professor Adjunto I da Universidade Federal do Rio Grande do Sul, Doutor em Direito pela Universidade de Munique - Alemanha, e orientador do referido trabalho.
} 


\title{
Fundamentos Conceituais para uma Sociologia da Dogmática Jurídica ${ }^{7}$
}

\author{
Cristiano Estrela da Silva
}

\section{RESUMO}

A presente dissertação objetiva analisar uma noção jurídica, a de dognática jurídica, sob um ponto de vista sociológico. Parte-se do estabelecimento de un marco teórico específico, Max Weber, e de uma reflexão eminentemente conceitual para, em un segundo momento, compreender a dogmática jurídica em um contexto de racionalização material do direito. Busca-se, neste contexto, captar o sentido da atividade dogmática tanto na elaboração de conceitos em abstrato quanto na solução de casos concretos.

${ }^{3}$ A Banca Examinadora foi composta pelo Professor Doutor Femando Atria, Professor da Universidade Adolfo Ibanez - Chile e Doutor em Direito pela Universidade Edimburgo, EU - Grä-Bretanha, pelo Professor Doutor Luís Fernando Barzotto, Professor Adjunto I da Universidade Federal do Rio Grande do Sul e Doutor em Direito pela Universidade de São Paulo, e pelo Professor Doutor João Maurício Leitão Adeodato, Professor Titular da Universidade Federal de Pernanbuco e Doutor em Direito pela Universidade de São Paulo. A referida defesa foi presidida pelo Professor Doutor Cláudio Fortunato Michelon Júnior, Professor Adjunto I da Universidade Federal do Rio Grande do Sul, Doutor em Direto pela Universidade Edimburgo, EU - Grä-Bretanha, e orientador do teferido trabalho. 


\title{
O Fundamento Legal da Alteração Judicial dos Juros nos Contratos de Crédito Bancário ${ }^{8}$
}

\author{
Carlos Cini Marchionatti
}

\section{RESUMO}

A atual dissertação envolve-se com a discussão dos juros remunetatórios nos contratos de crédito bancário em geral, que se tornaram tremendamente discutidos em âmbito jurisprudencial. O desenvolvimento do tema divide-se em duas pattes.

Na primeira parte, a dissertação examina a caracterização do contrato de crédito bancário e das instituições financeiras, intimamente relacionada à possibilidade da cobrança dos juros remuneratórios superiores a $12 \%$ ao ano, aos quais se limitam os contratos em geral. Desenvolve-se com o estudo das cláusulas legais e contratuais sobre os juros e os casos análogos, como os juros moratórios, a multa, a comissão de permanência, o regime de capitalização dos juros cobrados. A primeira parte completa-se com o tratamento dispensado à matéria no Direito brasileiro.

A segunda parte trata da revisão judicial do contrato de crédito bancário, distingue as hipóteses que justificam a intervenção judicial, relaciona-as às características atuais da lide processual e completa-se com as referências aos provimentos judiciais específicos às hipóteses da intervenção judicial.

Ao fim, contém um resumo das principais conclusões do desenvolvimento da dissertação,

\footnotetext{
${ }^{8}$ A Banca Examinadora foi composta pelo Professor Doutor Juan Malcolm Dobson, Professor da Universidad Nacional de Rosário - Argention e Doutor em Direito pela Universidade Nacional del Litoral - Argentina, pelo Professor Doutor Humberto Bergmann Ávila, Professor Adjunto I da Universidade Federal do Rio Gtande do Sul e Doutor em Direito pela Universidade de Munique - Alemanha, e pelo Professor Doutor José Carlos Moreira Alves, Professor da Universidade de São Paulo e Livre Docência em Direito pela Universidade de São Paulo. A referida defesa foi presidida pela Professora Dottora Véra Maria Jacob de Fradera, Professora Adjunta da Universidade Federal do Rio Grande do Sul, Doutora em Direito pela Universite de Paris II,UP II - PARIS, e orientadora do referido trabalho. Data da defesa: 23-07-2004.
} 


\title{
O Direito Fundamental ao Ambiente como Direito a Prestações em Sentido Amplo 9
}

\author{
Anizio Pires Gavião Filho
}

\section{RESUMO}

O propósito desta investigação é encontrar justificação racional para uma teoria jurídica do direito fundamental ao ambiente como um direito a prestações em sentido amplo. Para isso, deve ser justificada a vinculação jurídica produzida pela noma do direito fundamental ao ambiente, contida na disposição do art. $225 \mathrm{da}$ Constituição brasileira de 1988, com o caráter de regra ou de princípio. Será decisivo demonstrar que o direito fundamental ao ambiente pode ser compreendido como um todo, integrado por um feixe de posições fundamentais jurídicas, pertencente à categoria do direito a algo, estrutura que permite a sua configuração como direito fundamental a prestações em sentido amplo: direito à proteção, direito à organização e ao procedimento e direito a prestaçóes em sentido estrito.

\footnotetext{
-A banca foi composta pela Professora Doutora Véra Maria Jacob de Fradera, Professora da Universidade Federal do Rio Grande do Sul e Doutora em Diteito pelá Universidade de Paris II - França, pelo Professor Doutor Roger Raupp Rios, Professor da Universidade Ritter dos Reis e Doutor en Direito pela Universidade Federal do Rio Grande do Sul, e pelo Professor Doutor José Rubens Morato Leite, Professor da Universidade Federal de Santa Catarina e Doutor em Direito pela Universidade Federal de Santa Catarina. A referida defesa foi presidida pelo Professor Doutor Luis Afonso Heck, Professor Adjunto da Universidade Federal do Rio Grande do Sul e Doutor em Dixeito pela Universidade Federal de Minas Gerais, orientador do referido trabalho.
} 